\title{
Corrigendum
}

\section{THE DEVELOPMENT OF A REGIONAL PHONOLOGICAL FEATURE DURING A SEMESTER ABROAD IN ARGENTINA - CORRIGENDUM}

\section{Rebecca Pozzi \\ Robert Bayley}

https://doi.org/10.1017/S0272263120000303, published online by Cambridge University Press, 10 August 2020.

In the original publication of this article (Pozzi \& Bayley, 2021), the phrase "word type" appears several times where the phrase "lexical item" should appear instead. These instances are in the following locations within the article:

p. 117 , paragraph 1 , line 4

p. 119, four instances, including one in Table 3

p. 121, three instances, including one in Table 4

p. 124 , paragraph 3 , line 4

p. 124 , paragraph 4 , line 2

p. 125, paragraph 3 , lines $2-3$

p. 125, paragraph 4 , lines $2-3$

p. 127 , paragraph 3 , line 9

p. 127 , paragraph 3 , line 10

Any other instances of "word type" in the article not listed above are correct as published. The authors apologize for this error.

\section{REFERENCE}

Pozzi, R., \& Bayley, R. (2021) The development of a regional phonological feature during a semester abroad in Argentina. Studies in Second Language Acquisition, 43, 109-132. 